been clearer if instead of saying "in this design" the statement had read "for these experiments."

The argument about analysis of variance and an F-test being appropriate if there are more than two treatments, whereas a paired $t$-test is appropriate for two treatments, overlooks an important point: with two treatments, analysis of variance and a paired t-test are identical. The F-statistic in such a case is simply the square of the t-statistic, and the statistical significance of the observed difference between treatments is the same, regardless of which way it was computed.

Finally, the statement about the suitability of long strips was certainly not intended to refer to all on-farm experiments. In the paper, that statement began by citing the particular methodological research on which it is based. We took for granted that the reader would know to supply the qualifier "under the conditions of that research." (Not coincidentally, that research dealt with experiments similar to those discussed in the paper.) One might argue that such a qualifier should always be included when citing a research result, but commonly it is left unsaid, without causing any great misunderstanding.

Richard Thompson

Sharon Thompson

William Lockeretz

\section{A sustainable agriculture requires broad approach}

The commentary by Allen et al., Integrating social, environmental, and economic issues in sustainable agriculture (Volume 6, No. 1, page 34) was great. They clearly pointed out the existing imbalance between the search for specific on-farm strategies and the search for social, political, and economic structure for a sustainable agriculture. Lots of the former, little of the latter in our mainstream agricultural establishment.

Cultural, political, social, and ethical foundations for a sustainable agriculture have continuously been proposed by Wendell Berry, Wes Jackson, Marty
Strange, Gene Logsdon, Donald Worster, Gary Nabhan, Robert Rodale.... These scholars have thoroughly outlined the basic assumptions that have lead (and are still leading) agriculture to its current degrading path, raised essential questions, and wrote about possibilities for an agriculture that cares for the land and the people. Many of us working to create a healthier agriculture have been inspired by them and yet, for some reason, they are not acknowledged in the cited literature by Allen et al. or many other papers related to rethinking of our agriculture, integrating sociology, ethics, and justice in agriculture.

The ultimate measure of the quality and effectiveness of our agricultural research, education, and service should be reflected in farmers' livelihood, resurrected rural communities, landscape restoration, and social and economic equity for people in the food system here and elsewhere.

Kamyar Enshayan, Ph.D.
Sustainable Agriculture
Program
The Ohio State University
Columbus, OH 43210-1220

Response: Dr. Enshayan is quite right in citing the contributions of these writers--they have been among the first to influence the agricultural paradigm in the direction of sustainability. Our article was not intended as a comprehensive literature review, however, but an attempt to demonstrate that we need to move beyond the priorities of many sustainable agriculture programs newly established within agricultural institutions. Nonetheless, while we also acknowledge the seminal contributions of Berry, Jackson, Strange, et al., we think we need to go farther than they do in reconstructing agriculture in ways that will make it truly sustainable for all social groups. Their work focuses on the traditional American family farm as the beneficiary and ideal vehicle for sustainability. While this is an important focus, we believe it does not adequately encourage new agricultural forms that address the issues of the larger community which is a part of agriculture and is affected by it. Partic- ularly overlooked is the need to reconfigure race, class, and gender relations in ways that allow everyone--including women, people of color, the poor--to benefit equally from sustainable agriculture. This theme is elaborated in an article by Patricia Allen and Carolyn Sachs in issue 13 of the journal Science as Culture.

Patricia Allen, Debra Van Dusen, and Stephen Gliessman

\section{Supreme Court Allows Localities to Regulate Pesticides}

The U.S. Supreme Court has ruled unanimously that the Federal Insecticide, Fungicide, and Rodenticide Act (FIFRA) does not deny local authorities the right to regulate pesticides. However, the Supreme Court reaffirmed the right of states to pre-empt local authority, if they choose; states that do not already have laws concerning local pesticide authority may now tackle the issue. The decision applies only to local regulation of the use and sale of pesticides, not labeling, packaging, or initiation of health studies. The case began in 1985 when a Christmas tree grower in Casey, Wisconsin, was denied a permit for aerial spraying of pesticides on some of his land and sued the local government. 